\title{
The seduction of Sarah: travel memoirs and intercultural learning
}

\author{
Barbara E. Hanna, Queensland University of Technology \\ Juliana de Nooy, University of Queensland
}

An autobiographical narrative by an expatriate Australian journalist, Sarah Turnbull's Almost French: A New Life in Paris dominated Australian bestseller lists for 2002, outselling all non-fiction bar the Guinness Book of Records. Heavily promoted in book outlets in Australia, it also benefited from vigorous word of mouth publicity: Almost French spontaneously circulated amongst Australian students of French, and, even closer to home, was recommended by a wide cross section of the authors' acquaintances: 'You've been to France, you'll love this.' Since its original publication, the book has also been released in US and UK editions. This then is an account of intercultural experience with enormous popular appeal. How does this book deal with issues of intercultural communication, and what are the lessons to be learned from it?

Our analysis proposes that the book participates in a complex game of generic assignation, whereby the lure of one genre, a certain kind of travel memoir, is used to manoeuvre readers into a position where they read the book as a treatise on intercultural difference. We suggest that the particular form of genre hybridity attempted is a delicate enterprise, in that the intercultural lessons on offer risk being overshadowed by the expectations readers bring to the genre of the contemporary travel memoir set in France. In making a play for audience attention while attempting to impart intercultural knowledge, the book's narrator is positioned in a way parallel to that of the teacher of intercultural communication who seeks to use narratives as pedagogical resources. For 
this reason, our paper draws pedagogical conclusions from its literary/textual analysis, bridging disciplines in a way that mirrors Turnbull's bridging of genres.

\section{Intercultural narratives}

Stories of encounters with the cultural other are gaining in importance as a means of increasing student understanding of cultural difference (cf. Álvarez and Beaven 2003, Pavlenko 2001, Ros I Solé 2004, Thurlow 2004). The intercultural narratives most often proposed for classroom use and attracting the most scholarly attention tend to be either literary (intercultural autobiographies, migrant life-writing) or conceived in and for a pedagogical context (student diaries, accounts of critical incidents). Yet the genres most readily available for telling of intercultural experiences, and reaching the widest public, fall into neither of these categories, but are variations on the personal anecdote, whose written form is the travel memoir. ${ }^{1}$ Amongst Anglophone readers this genreand in particular the year-in-France-cum-home-renovation memoir (of which Peter Mayle's A Year in Provence is the iconic example)_-boasts a wealth of publications and enviable sales figures and even-a sure indicator of its conventionalized statusseveral recent spoofs (Bouchet 2004, Clarke 2004, 2005).

Despite detailed descriptions of different ways of life, these entertaining narratives do not lend themselves in any obvious way to intercultural learning. Narrator and reader are invariably positioned as mirrors of each other, and cultural complicity is fostered between them such that there is no need to reassess incidents in terms of values other than one's own. The French-based sub-genre trades on the mythical charm of France, a country populated by a stock cast of colourful characters, whose antics in comic adventures and tales of calamity are bound to amuse the decidedly more normal Anglophone reader. Characters are caricatures: more memorable than any insights into different cultural values are the bureaucratic bunglers, eccentric workmen and flirtatious foreigners populating these stories. The conventions of the genre thus work to entrench stereotypes, such that the other remains firmly other.

Given the enormous reach of these texts, the idea of diverting these conventions to a different purpose is tantalizing. This paper explores the possibility—and the

\footnotetext{
${ }^{1}$ In another study the authors have looked at oral accounts of study abroad experiences of Australian students (de Nooy and Hanna 2003).
} 
difficulty —of harnessing the travel memoir set in France to the task of facilitating cultural understanding. The problem is one of shifting predictable patterns, and our case study, Turnbull's Almost French, takes up the challenge with mixed results, raising questions about the preconditions for intercultural learning. Although found on the same bookshop shelf as Mayle's volume, Almost French differs from it and its kind in significant ways. Whilst the Australian edition's jacket publicity evokes the charm of Paris, promising a tale of love in 'a magical city,' Turnbull attempts to draw the reader towards an understanding of many aspects of French culture that initially appeared unfathomable to her. From the account of her arrival at the airport, the positioning of narrator and reader challenges the conventions of the genre. At cocktail parties, on the phone, in shops and in the street, it is Turnbull herself who is the colourful and bizarre character among the normal French. The narrator thus others herself and invites readers to do the same: to see the Anglophone as the foreigner, to view Australian norms from another perspective.

Turnbull repeatedly invokes la séduction (ix, 23, 55, 139, 170, 179) as a French quality to which she is susceptible, as she falls for the charms of Paris and of Frédéric. ${ }^{2}$ Ross Chambers' discussions of narrative, however, allow us to see a further seduction at work in Almost French. In Story and Situation and Room for Maneuver, Chambers views narrative as a seductive enterprise by the narrator aimed at shifting the desire of the narratee. It can be argued that Turnbull's book sets up a narrative seduction that exploits the travel memoir genre to present opportunities for intercultural learning. Success is not, however, guaranteed, for it depends on enticing readers away from the powerfully seductive myth of a stereotypical France that attracted many of them to the book in the first place. Analysis of these competing seductions- the allure of the myth of France and the persuasive powers of Turnbull's narration-will reveal the role of genre in determining the intercultural outcome of readings, with implications for intercultural storytelling more generally.

\section{A tale of two genres: travel memoir?}

Almost French: A New Life in Paris is marketed as a travel memoir in Australia, and although the UK edition (Turnbull 2003a) is published by specialists in cross-cultural

\footnotetext{
${ }^{2}$ All quotations are from the Australian edition (2002).
} 
training manuals, and is listed in their catalogue in the section 'Managing across cultures,' high street bookshops display it in the travel memoir section. The US edition (2003b) places it even more firmly in this category. The revised title-Almost French: Love and a New Life in Paris-emphasizes romance and the book sits comfortably amongst other bestselling volumes such as:

\section{A Farmhouse in Provence: An American Finds Old Stones, New Wine and Love Among the French (Henry 2000) \\ French Spirits: A House, a Village, and a Love Affair in Burgundy (Greene 2002) The Olive Farm: A Memoir of Life, Love and Olive Oil in Southern France (Drinkwater 2002)}

While these titles suggest the love story as an alternative model to the travel memoir genre, the mutual inclusiveness of France and Romance in the popular imagination implies that any tale of travel in France is by definition already a love story. A journalist breathlessly reports:

Sarah moved around Eastern Europe before settling in Paris-the City of Love!

And the reason she moved-what else, love!

While travelling in Bucharest she met a French lawyer, fell in love and followed him to France. It sounds like the start of a romance novel. Sarah not only married her dream, she's living her dream. (Australian Broadcasting Corporation [ABC] 19 Jun. 2002)

Indeed, in another summary, romance overshadows the travel memoir to the point where the book becomes a novel: 'Almost French, the debut novel by journalist Sarah Turnbull, is a love story between man, woman and city: she's Australian, he's French and the town is Paris!' (ABC 24 Apr. 2002)

Resisting the romantic reading, we point out that nightmare moments abound in this book where love is arguably a minor theme. As a more careful review remarks, 'Turnbull tells readers less about love than new life' (Publishers Weekly 2003), and the author's description of that new life in many respects defies the book's positioning within the genre of travel memoir. While the early chapters are chronologically arranged, recounting Turnbull's arrival, decision to stay, struggle to find work, and move to the centre of Paris, simultaneously each chapter seeks to analyse a perplexing aspect of French culture. Topics include intellectualism, dinner parties, small talk, dress, family ties to place, relations between the sexes, and, throughout the book, 
communication. Far more important than the narrative of relationship milestones on the way from chance meeting with Frédéric in Chapter 1 to marriage in the Epilogue is the story of the passage from incomprehension and ineptitude in a foreign culture to understanding and competence.

Although the postcard view of France promised by the genre is certainly present, Turnbull most often recognizes and labels it as such—'Yes, I admit, I'm carried away on a kaleidoscope of clichés straight out of a trashy romance novel’ $(22$, cf. 128, 170) in order to provide an alternative view. In fact the 'clichéd visions' (ix) are identified in the Prologue as what Turnbull brought to Paris. They are a starting point, assumed to be shared by the reader, who is invited to move on, to accompany Sarah on her journey of discovery of Frenchness from a French perspective. This is not to say that Turnbull's account is always successful in disentangling itself from clichés, nor that her analysis is faultless: despite regular recognition of the diversity of French culture, the book also contains over-extrapolations from Parisian bourgeois circles to Paris in general to France as a whole. Yet the very presence of analysis, even if flawed, encourages the reader to engage with instances of cultural difference as indicative of divergent patterns of cultural behaviour, rather than as a colourful but one-dimensional backdrop to her adventures.

Emphasizing the learning that has marked Turnbull's six years in France are statements that could have come from an intercultural communication textbook, heartfelt but nonetheless didactic remarks about how 'you can’t measure your behaviour by familiar yardsticks’ (39):

\footnotetext{
How do you explain the nuances of the way people interact when you've never questioned them yourself before? How can you construct neat answers for customs and codes of behaviour you have taken for granted since birth? (70)

I was too consumed by the effort of trying to adapt to my new home to see the reaction of Frédéric's relatives within the context of a culture. Instead, I did exactly what you shouldn't do, what I've been doing all along in France. I took it personally. (88)
}

My eyes don’t see what Frédéric sees—or at least they see it differently.' (151) and learn a way of communicating that works in France. (187) 
The film forced me to face facts-my style of communicating doesn't work in France. It had to change. (273)

\section{Intercultural guidebook}

It can be argued then that although the book is labelled a travel memoir, its purpose parallels that of a book Turnbull cites on several occasions: Polly Platt's French or Foe (1998). Openly didactic rather than seductive, French or Foe (along with other volumes attempting to explain French culture) is sold, not as travel memoir but as intercultural guidebook or travel guide, a genre addressing a more limited readership already actively seeking answers to intercultural questions and including:

Savoir-Flair: 211 Tips for Enjoying France and the French (Platt 2000)

Au Contraire! Figuring Out The French (Asselin and Mastron 2001)

Sixty Million Frenchmen Can't Be Wrong: Why We Love France but Not the

French (Nadeau and Barlow 2003)

Culture Shock! France: A Guide to Customs and Etiquette (Taylor 2003)

Turnbull's book thus plays between genres, one more clearly flagged than the other.

This was apparently a deliberate choice: interviews indicate that Turnbull felt she could 'fill a niche between the "renovating a house in the countryside" genre and more serious cultural studies' (Wyndham 2003). Thus, although the book is pitched as travel memoir, unlike Mayle in A Year in Provence or Greene in French Spirits, Turnbull is not satisfied to remain bemused by the curious French, but rather seeks to understand perplexing incidents as part of wider cultural patterns. However, in order to impart her new knowledge, she must persuade the reader to exchange readymade romance for lessons in cultural difference. Her strategies include framing her narrative as an 'adventure' in both Prologue and Epilogue (ix, 309) such that the learning is a question of 'solv[ing] mysteries' (135) rather than taking instruction; holding out the promise of a rich reality (ix, 118) that eludes the romantic gaze; and, more subtly, manipulating the possibilities for reader identification with her life in Paris, that locus of desire predetermined by the travel memoir genre, through constantly adjusting her speaking position. Nevertheless, these seductive measures are not successful with all readers, as we shall see.

The ambiguity of genre in Almost French prevents the reader from simply settling into comfortable complicity with the narrator. The reading position provided by the genre of the travel memoir (identification with the narrator through shared values) is destabilized 
as Turnbull recalibrates her cultural norms. She becomes a moving target for readerly identification as she invites the reader to continue to shadow her. This is achieved through frequent variation in the distance between Turnbull as narrator (the sujet de l'énonciation) and Turnbull as protagonist (the sujet de l'énoncé, Benveniste, cf. Chambers 1984, 1991). While the protagonist steadily evolves from Australian tourist to 'almost French' resident of Paris, the narrator's speaking position repeatedly oscillates between that of the newly arrived and uncomprehending Sarah and her wiser, more reflective avatar. This produces double-edged accounts of incidents: Turnbull explains her incomprehension in a way that arouses sympathy from the Australian reader, but she simultaneously takes an ironic distance from her self-portrait that unsettles the affinity. Thus the tale of a disastrous bourgeois cocktail party shows an almost caricatured Australian girl in Doc Martens attempting to strike up chatty conversations by enthusiastically admiring the furniture and encouraging guests to get stuck into the champagne (63). Similarly double is the mocking description of her own propensity to dress down when there is no reason to dress up (130, cf. x), accompanied by a bafflement easily understood by her intended readers: 'Underpinning Frédéric’s reaction to tracksuit pants is a concept which to me is totally foreign: looking scruffy is selfish' (131).

This ironic distance sharpens into a clear split between Australian and French ways of seeing and the narration glides from one towards the other. At the cocktail party, Sarah articulates her confusion as an Australian: 'Could the rules be so different in France? But then how else are you supposed to get the ball rolling if not with preliminary questions and conversation?' (64). Having marked this point of contact with her intended readers, she leads them elsewhere. She moves towards a speaking position from within French culture, at first giving voice to Frédéric’s interpretation, and eventually accepting French rules of social engagement. Thus it is in Frédéric’s voice in the first instance that we hear that her behaviour might be interpreted as clumsy, intrusive and uncultured by French standards (65). Eventually, however, it is Sarah herself who 'do[es]n't feel compelled to fill silences' (273), who is able to explain conversation as a game of skill and to recount her wins. The turning point for Turnbull occurs she sees the film Ridicule, in which a provincial baron must learn the art of verbal jousting in order to gain an audience with Louis XVI (271-273). If Frédéric’s role in Sarah's transformation resembles that of the kindly aristocrat who coaches the 
baron, that role is adopted by Turnbull in relation to the reader. The reader receives instruction in the goals of interaction and the criteria for success.

Similarly, while not renouncing her right to wear trousers that make her 'look like a baby elephant' (131), Turnbull guides the reader towards Frédéric’s (and by extension a French) perspective on casual Anglo dressing, detouring from Paris to London to a hypermarket in Boulogne-sur-Mer filled with British day-trippers. She recounts her own shift in attitude when, during a weekend trip across the Channel, Sarah reacts to Londoners' eclectic combinations of styles and colours through eyes now accustomed to Parisian norms: ““Look what they’re wearing!” I exclaimed to Frédéric’ (133). But the narrator Turnbull continues to hover between speaking positions, touching base with the reader's world view_-'You might think this is ridiculous' (138)—at points during her exposition of French aesthetic principles, and tempting them towards a new view.

Emblematic of Turnbull's approach to French culture is the episode of the new window. In a significant departure from stories of the loving restoration of traditional homes to their former glory, the home improvements in Sarah's apartment open up an entirely new (and illegal) window. And just as the book shies from perpetuating 'clichéd visions' of Paris, the renovation literally provides a new way of seeing the city. 'It’s like a painting' (236 ) says Frédéric of the view, but its composition differs from that of the Monet painting of their street at the Musée d'Orsay (235). This is highlighted in the jacket cover of the Australian edition (Figure 1): 'Sarah' surveys a view of Paris comprising chimney pots and satellite dishes, zinc roofs and high rise. But this window does more than provide a room with a view: its installation requires that Turnbull be actively involved in negotiating Parisian rules of renovation, legal or otherwise. Indeed the 'eye-opener' (239) in this architectural adventure has been the revelation that 'In Paris, there is a way around almost every rule' (239). 


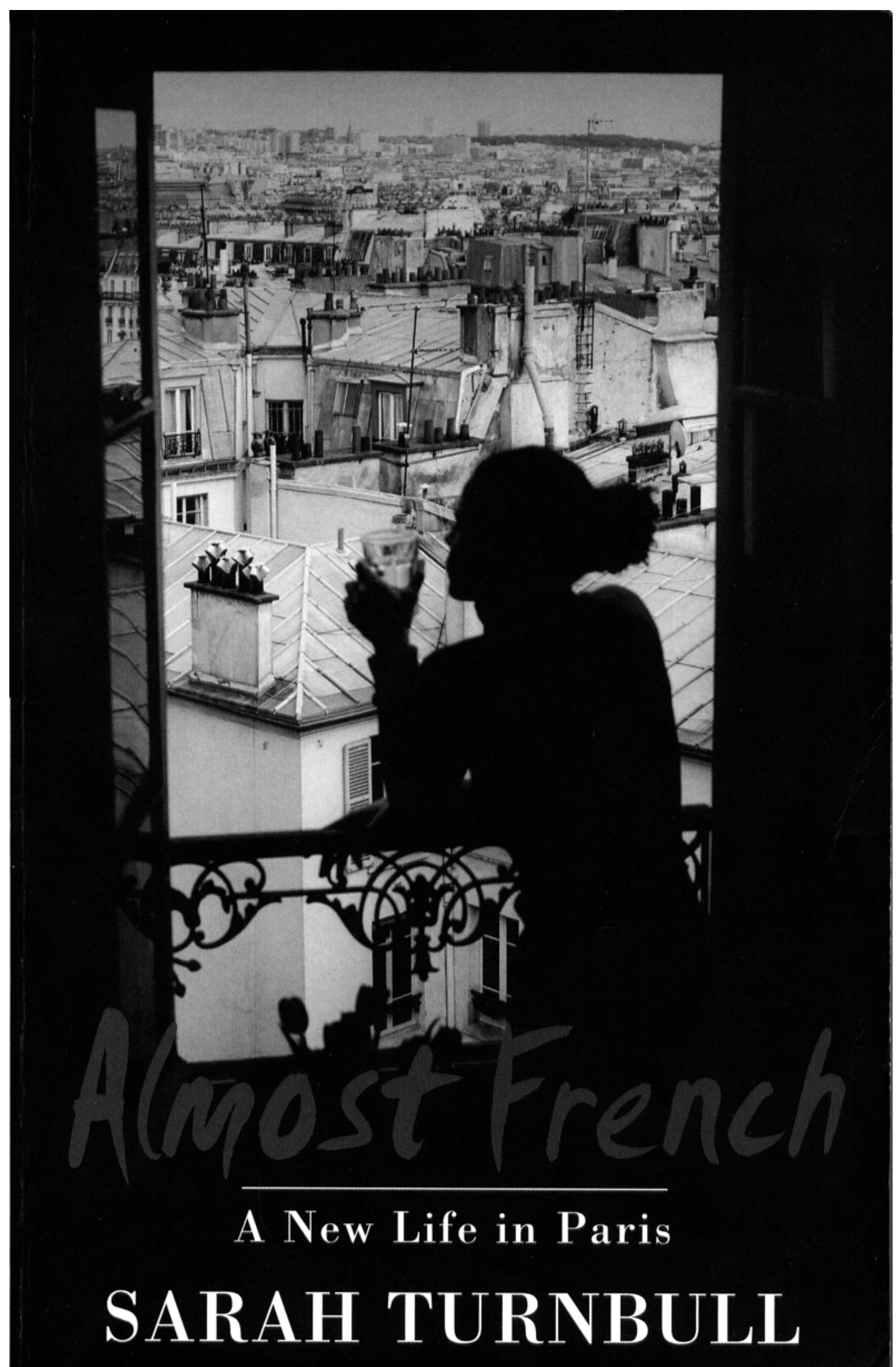

Figure one: the Australian cover.

'Tunnell[ing]' (231) through a 'blind wall' (227), 'hoping for a glimmer of light' (232), the quest for her window onto Paris reflects Sarah’s determination to achieve an insider's perspective on French culture. The blind wall is 'a source of frustration, a 
solid, sealed barrier' (227) not unlike the cultural barriers she has confronted, and as the effort of tunnelling through suggests, this is not a view that can simply be acquired like a postcard. The reader, like Sarah, is required to chip away at what seemed like rocksolid certainties. As Turnbull explains when she struggles to see beauty in a Blockhausstrewn beach under a leaden sky: ‘At heart, it isn’t about scenery: it is about who we are, individually, and what we are willing to become' (154). And for those she tempts towards transformation, the reward Turnbull promises is a perspective 'far richer, a thousand times better' than the stereotyped image of France (ix).

\section{L'invitation au voyage}

The extent to which readers will be persuaded to share the narrator's vision- to exchange the romantic stereotype for the cultural insights Turnbull proposes-is thus uncertain. For many, the easy pleasures of the genre of the contemporary travel memoir set in France tend to obscure the new view available. Thus the window entirely disappears on the cover of the US edition in favour of the tourist's Paris (Figure 2): a soft-focus image of le quartier St Michel overlaid by a postcard of a kiss on the Pont des Arts. 


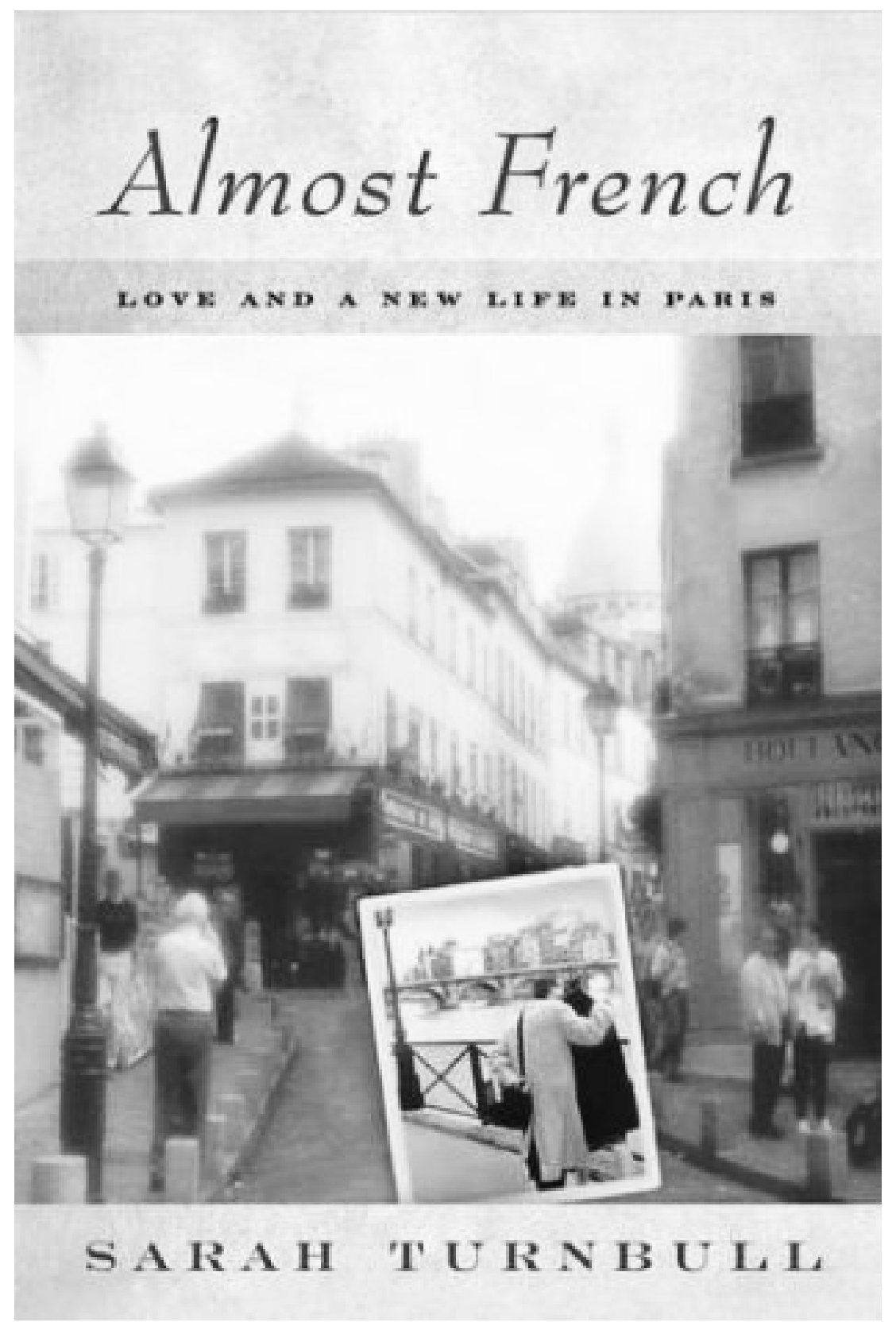

Figure two: The US cover.

In parallel fashion, the intercultural import of Turnbull's tale has a tendency to disappear in accounts of the book. Much of the paratext of Almost French (publicity, jacket blurb, interviews, reviews) constructs an itinerary through the book that, although a voyage of discovery, is very much the discovery of what Cryle (1998) terms the 'familiar foreign': romance, restaurants, fashion shows, surly shopkeepers, and small spoilt dogs all make their appearance. Turnbull's story is therefore often read as simply another evocation of the quaint charm of Paris and those romantic Frenchmen. As Almost French surged through bestseller lists, it was not the intercultural learning 
narrative that was highlighted in reviews and other reader comment, and those voting Turnbull’s life ‘the most envied' (Wyndham 2003) surely overlooked the miserable marginalization at dinner parties, the humiliating inability to accomplish simple tasks which marked her early days in Paris. While accounts of culture shock may be characteristic of 'settler writing' (Álvarez and Beaven 2003), they are not the most salient part of Turnbull's story for the majority of readers. It was Turnbull's fortune (or misfortune) to find herself in a French subculture that corresponded so precisely to the stereotyped expectations of an Anglophone audience. Consequently, in accepting l'invitation au voyage offered by the book, readers have not necessarily taken up Turnbull's further invitation to revise these expectations, to arrive at a hitherto unknown destination.

We might take, as one example, the Myth of France as the land of endemic elegance. Paris is indeed a capital of high fashion and readers are duly given accounts of interviews with couturiers and fashion parades that Turnbull covers as journalist. The transformation of her own wardrobe is also recorded: her airport arrival in 'clumpy sandals' and safari shorts is repeated at various points as a kind of 'before' shot. Commentators have highlighted this moment together with the 'lesson in French dress standards' (130) represented by Frédéric’s distress at her attempt to wear tracksuit pants in the street. The temptation is to read her subsequent adaptation as, if not exactly a rags-to-riches story, at least one of sartorial salvation, of deliverance from Australian dagginess to enlightened elegance. This interpretation resembles that of Turnbull's mother, who, in casual sweater and slacks, feels 'hopelessly out of place' on the stylish Rue du Faubourg St-Honoré (140). For subsequent visits she packs smart suits and high heels. Lesson learnt? Maybe, but it is not necessarily the one her daughter wants readers to learn as she adds a generally overlooked qualification: the revised holiday wardrobe is 'perfect for Rue du Faubourg St-Honoré but conspicuously inappropriate for tripping through French country markets' (140). This comment is a loose thread in the smooth stitches of the story of the uniformly elegant French, a loose thread we can use to unravel that story. Here is a clue that different contexts within French culture require different clothes; that blanket generalizations about The French fail to take into account even the diversity of clothing requirements within the one subculture. That is, Turnbull again provides the material needed to destabilize the stereotype. Further hints are the various points at which Frédéric is not aligned with elegance (for example 21- 
22). Indeed, if Sarah's dress changes, so does Frédéric’s: as was the case with the apartment, the renovation of his wardrobe distances it from a traditional style (his grandfather's cravats), as he buys Australian Country Road designs (296). Yet how many reviewers and readers tell us that Frédéric is the quintessentially, tautologically, elegant Frenchman? His old school friend, portrayed with a revealing gap between torn tee shirt and 'slipping shorts' (28), is completely ignored in the reviews (and is perhaps seen only as an idiosyncratic exception). In these readings, only those elements of the story that concur with the pre-existing picture of Frenchness are retained.

This is not to suggest, however, that readers finding confirmation of clichés cannot learn any intercultural lessons from the book:

The two Queenslanders were all dressed up to explore the Paris neighbourhood that's the main setting for [...] Almost French. They were excited to spot the author in the street [...] and stop for a chat. 'After reading your book, we thought we'd better make an effort,' said the woman in black high heels and stockings. (Wyndham 2003).

No doubt these well-dressed explorers did not need Almost French to tell them about French elegance. However, even if, like Turnbull's mother, they over-extrapolate this dress code to country markets, even if their image of French culture has not changed, they have still learnt something from the book, namely that their own vestimentary presentation, rather than being neutral, is available for interpretation. So whilst they may not see France differently, they have learnt to see themselves through other eyes. That is, the mirror held up by Almost French, rather than simply reflecting an Australian view back to Australian readers, allows us to see what those Curious French might think of us.

There is nonetheless a clear division between two quite different responses to Turnbull's book, readings we could characterize broadly as 'starry-eyed' and 'intercultural.' The division is illustrated by the two types of letters Turnbull is said to receive: 'Some say her evocative book makes them want to rush to France; many thank her for expressing the loneliness and confusion of their own expat life there' (Wyndham 2003). How can the same book conjure up such opposing visions of France? More pertinently for teachers of intercultural communication, what mechanism enables some readers to make the interpretative leap towards revising stereotypes and, conversely, what hinders others? 


\section{Competing seductions}

The discrepancy between readings can be partly explained by the competing seductions at work. As we have seen, Almost French harnesses the seductive strength of the myth of France in order to lure readers towards a reassessment of that idealized image. This is a precarious strategy, not in sales terms, but in intercultural ones. The reader's desire is engaged in order to divert it, but the danger is that the pursuit of French romance blinds readers to Turnbull's more subtle seduction.

It is not only the power of myth, however, that predisposes readers to finding romantic clichés in a book where they are challenged. The 'starry-eyed' readings of Almost French bear testimony also to the power of genre in determining the reader's engagement with the text. Pavlenko (2001, 213, 218) emphasizes the need to approach language-learning memoirs and other cross-cultural autobiographies as genres, to focus on their rhetorical shaping as much as their informational value. Furthermore, just as Turnbull's writing is shaped by rhetorical conventions, so too is the way it is read. The book has been insistently marketed as a travel memoir, and thus it is with the expectations of this genre-glamour, excitement and the flavour of an exotic locationthat most readers open Almost French. As Gerhart $(1991,156)$ remarks, 'genres frame readers as well as texts', and clearly not all readers are prepared to relinquish the genre hypotheses with which they come to the book. Reinforcing Freadman and Macdonald's thesis that genre is not simply constituted by textual features but is an act of interpretation that in turn largely determines further interpretations of a text (Freadman and Macdonald 1991, 24), we find reluctance on the part of some readers to revise their expectations, to register either Sarah's loneliness or her insights into Australian, as much as French, behaviour.

For Chambers, storytelling can change people when the seductive powers of the narration are able to redirect the desire of the reader/listener. In the case at hand, the shift is from a desire for the set pieces of the Life in France memoir towards a desire to see through different eyes, and the first condition necessary for it to take place is an acceptance of the detour in genre. It is when readers allow themselves to be enticed away from the predictable delights of the travel memoir towards the lessons of the travel guide that the 'intercultural’ reading emerges. 
Now, shifting genre is not unlike the process of elucidating an intercultural incident. In each case, a narrative is revisited through a different interpretative framework. Reframing the genre entails rereading, relativizing and reconsidering, skills we associate with intercultural competence. As a book that is 'betwixt and between' genres (to echo Turnbull's characterization of her expatriate condition, 298), Almost French invites readers to move between one set of reading practices and another. As such it provides opportunities - but only for those readers who can make that shift- to experience first hand, and even as armchair travellers, what it is to participate in an intercultural journey.

If Almost French has potential for intercultural learning it also has lessons for teachers of the intercultural, who use narrative to illustrate points of difference in cultural world views. Thurlow (2004) has called for such teachers to be autobiographical storytellers, and for our stories to be gritty, uncomfortable, if necessary. Rather than presenting the practice of intercultural communication as a straightforward path to harmony, happiness and, indeed, envied lives, we need, he says, to teach our students that it can involve confronting, even intractable challenges to our most deeply held beliefs and values. Our analysis of the fate of Almost French, however, suggests that merely disseminating stories, autobiographical or otherwise, in the hope of demonstrating this principle, is not enough: the impact of a text depends less on its content than on the way in which readers engage with it.

While we can never ultimately control the ways in which our stories are taken up, we need to be aware of prevailing myths and of the side effects of our narrative seductions and framings. In offering our stories, we must be mindful of genre norms and the kinds of reading practices they invite: these have profound effects on the capacity to interpret incidents in terms of cultural values other than one's own. A humorous anecdote of cultural misunderstanding placed to liven up the language class, a horror story that students accept at face value, an intercultural novel studied in literary terms: none of these necessarily provides any payoff in intercultural terms. All can be interpreted by students in ways other than we intend, be this to confirm the charm of a Parisian life, or the 'weirdness' of other cultures, the other's otherness. That is, following an interpretative path more travelled, students may retain from our stories only what they 
already knew, missing the message calculated to make them question those very expectations. The pedagogical use of narratives thus needs to involve not just the story but the framework available for its interpretation. Working with students to make explicit the conventions of various kinds of travellers' tales, focusing on the positioning of the narratee that is favoured in stories of crazy foreigners can develop reflexes for reframing everyday intercultural tales outside the classroom, not ignoring the entertainment value, the sunshine of romance and home renovation, but not being blinded by them to potentially disruptive intercultural lessons.

\section{Reference list}

Álvarez, I. \& Beaven, T. 2003, 'A Life in the Sun: Accounts of New Lives Abroad as Intercultural Narratives', unpublished conference paper, International Association for Languages and Intercultural Communication Conference: The Intercultural Narrative. Lancaster.

Asselin, G. \& Mastron, R. 2001, Au Contraire! Figuring Out the French, Intercultural Press, Yarmouth, Me.

Australian Broadcasting Corporation 24 Apr. 2002, Radio broadcast summary [Online]. Available at: http://www.abc.net.au/rn/arts/nclub/stories/s539504.htm [Accessed 23 Jan. 2006].

-19 Jun. 2002, Radio broadcast summary [Online]. Available at: http://www.abc.net.au/sydney/stories/s585341.htm [Accessed 23 Jan. 2006].

Benveniste, E. 1966, Problèmes de linguistique générale, Gallimard, Paris.

Bouchet, B. 2004, French Letters: Under the Provence Sun: An Incredible Tale of Fathers, Scams and Lavender Moussaka, Hodder Headline, Sydney.

Chambers, R.1984, Story and Situation, University of Minnesota Press, Minneapolis. 1991, Room for Maneuver: Reading (the) Oppositional (in) Narrative, University of Chicago Press, Chicago; London.

Clarke, S. 2004, A Year in the Merde, Random House Australia, Sydney. 2005, Merde Actually, Random House Australia, Sydney.

Cryle, P. 1998, 'Detouring via the Other: Representations of Frenchness in Some Australian Advertisements', unpublished conference paper, Australian Society of French Studies Conference, Melbourne.

de Nooy, J., \& Hanna, B. E. 2003, 'Cultural Information Gathering by Australian Students in France', Language and Intercultural Communication, 3.1, 64-80.

Drinkwater, C. 2002, The Olive Farm: A Memoir of Life, Love and Olive Oil in Southern France, Penguin, New York.

Freadman, A. \& Macdonald, A. 1992, What is this thing called 'genre'?: four essays in the semiotics of genre, Boombana Publications, Mt Nebo, Qld.

Gerhart, M. 1992, Genre Choices, Gender Questions, University of Oklahoma Press, Norman, Oklahoma; London.

Greene, J. 2002, French Spirits: A House, a Village, and a Love Affair in Burgundy, William Morrow, New York.

Henry, M. R. 2000, A Farmhouse in Provence: An American Finds Old Stones, New Wine and Love among the French, iUniverse.com, Lincoln, Neb. 
Mayle, P. 1990, A Year in Provence, Knopf, New York.

Nadeau, J.-B. \& Barlow, J. 2003, Sixty Million Frenchmen Can't Be Wrong: Why We Love France but Not the French, Sourcebooks, Naperville, Ill.

Pavlenko, A. 2001, 'Language Learning Memoirs as a Gendered Genre', Applied Linguistics, 22.2, 213-40.

Platt, P. 1998, French or Foe?: Getting the Most Out of Visiting, Living and Working in France, Distribooks International, Evanston, Ill.

-2000, Savoir-Flair: 211 Tips for Enjoying France and the French, Distribooks International, Evanston, Ill.

Publishers Weekly, 16 Jun 2003, Review of Almost French [Online]. Available at: http://www.amazon.com/exec/obidos/tg/detail/1 1592400388//qid=065445965/sr=11-1/ref=sr_11_1/002-26084073723230 ? $v=$ glance\&s=books\&vi=reviews [Accessed 23 Jan. 2006].

Ros I Solé, C. 2004, 'Autobiographical Accounts of L2 Identity Construction in Chicano Literature', Language and Intercultural Communication, 4.4, 229-241.

Taylor, S. A. 2003, Culture Shock! France: A Guide to Customs and Etiquette, Graphic Arts Center Publishing Co., Portland, Or.

Thurlow, C. 2004, 'Relating to our Work, Accounting for our Selves: The Autobiographical Imperative in Teaching about Difference', Language and Intercultural Communication, 4.4, 209-228.

Turnbull, S. 2002, Almost French: A New Life in Paris, Bantam Australia, Sydney. 2003a, Almost French: A New Life in Paris, Nicholas Brealey, London. 2003b, Almost French: Love and a New Life in Paris, Gotham, New York.

Wyndham, S. 11 Jan. 2003, 'Most Envied Life', Sydney Morning Herald [Online]. Available at: http://www.smh.com.au/articles/2003/01/10/1041990089948.html. [Accessed 23 Jan. 2006]. 